\title{
How to Evaluate Human Capital?
}

\author{
Franko Milost \\ University of Primorska, Koper, Slovenia
}

\begin{abstract}
A company is usually founded by individuals striving to achieve their own or broader goals. Goal achievement related to a company's operations is called business or the business process. Human capital (man's work, employees) is an important element of the business process, however its value is not disclosed on the assets side of the classical balance sheet. In order to shown assets, human capital has to be evaluated. Evaluation can be made in monetary or non-monetary terms. Non-monetary models for evaluating human capital include organisational and behavioural variables. These variables are not expressed in monetary terms, however, based on changes in their quality, one can assume the increased or decreased value of human capital within the company. The value of non-monetary models should not be underestimated, however monetary models are of greater importance. In this article, the most significant non-monetary and monetary models of human capital evaluation are discussed. Among non-monetary models the Michigan, Flamholz, and Ogan models are discussed. Among monetary models the replacement costs model, the opportunity costs model, the discounted wages and salaries model, and originally created dynamic model are discussed. A descriptive approach is used to identify the basic characteristics of existing models for evaluating human capital. According to these findings a different approach is taken in developing an original model. Dynamic model can efficiently overcome most of the practical problems and can be used as an appropriate estimator of human capital value expressed in monetary terms. The research limitations are that the dynamic model has not been sufficiently verified in practice. The model could prove to be directly applicable in those enterprises that would like to define the value of their human capital.
\end{abstract}

Keywords: human resource accounting, human capital, financial statements, models of human capital evaluation

\section{Introduction}

Man's work is an important element of the business process. However, apart from its role as a means of production, products, and services, its value is not disclosed on the assets side of the classical balance sheet. Are there any solid grounds for such consideration of work? Does such consideration of man's work result from underestimating the meaning of this element of the business process? And finally, is work not (employees, human potential, human capital) a factor that has a crucial influence on successful business operations? These and similar questions are within the scope of human resource accounting.

Findings on the value of human capital are not new. In fact, its value has already been well recognised by pre-classical economists who treated man as an element and source of the national treasure. Over time, this

Franko Milost, Ph.D., Associate Professor of accounting, Faculty of Management, University of Primorska.

Correspondence concerning this article should be addressed to Franko Milost, Faculty of Management, Cankarjeva 5, 6000 Koper, Slovenia (SI). E-mail: franko.milost@fm-kp.si. 
knowledge underwent the process of maturation, nowadays, however, human capital finds its position in financial statements only exceptionally.

This article identifies the most significant non-monetary and monetary models of human capital evaluation. Among non-monetary models are presented the Michigan, Flamholz and Ogan model. Among monetary models are presented the replacement costs model, the opportunity costs model, the discounted wages and salaries model. Additionally, originally created dynamic model is also presented.

\section{Models of Human Capital Evaluation}

Human capital may be disclosed among the assets on a balance sheet only if it is expressed in value terms. In order to disclose human capital among balance sheet items, one must find a proper method for measuring its value. So far, some monetary and non-monetary models have been developed for this purpose (Brooking, 1996; Edvinson \& Sullivan, 1996; Sawalia, 1999; Edvinson \& Malone, 1997). Some of the most important models are outlined below.

\section{Non-monetary Models for Evaluating Human Capital}

Among the non-monetary models, the Michigan, Flamholz, and Ogan models are presented respectively below: The first two models are purely non-monetary, whilst the third one is combined, since it includes both monetary and non-monetary methods of evaluation.

\section{The Michigan Model}

The very first ideas of non-monetary evaluation of human capital can be traced to the works of researchers from the Institute for Social Research, which operates under the umbrella of the University of Michigan. The researchers of the aforementioned Institute shaped the model known as the Michigan or Likert model (named after the leading researcher of the Institute). The model defines variables that are likely to influence the effectiveness of individuals in an organization and, therefore, the successful operation of a human organization per se (Likert, Bowers, \& Norman, 1969, p. 14). The Michigan model aims at indirect definition of the value of human capital in an organization. It does not enable determination of their initial value, but rather monitors value changes resulting from changes within the organizational climate. Despite the aforementioned, and though there are numerous open questions to which the authors of the Michigan model have found no suitable answers (i.e., the question of various interpretations of such results), Flamholz is of the opinion that the Michigan model represents the most successful trial of the non-monetary evaluation of human capital in an organization (Flamholz, 1982, p. 23).

\section{The Flamholz Model}

Contrary to Likert, Flamholz shaped his non-monetary model of human capital evaluation in terms of the individual. He wanted to explain factors that influence the value of an individual in an organization. This model consists of behavioral and economic variables.

It is based on the assumption that the value of an individual in an organization depends on two interrelated variables, namely:

(1) the individual's conditional value;

(2) the probability of maintaining organizational membership. 
The individual's conditional value is determined as the current value of future services that may be rendered by an individual in an organization during his/her expected working life (Flamholz, 1972a, p. 668). Flamholz has tested his model in case of evaluating human capital in a company registered for services in the area of accounting and business finances (Flamholz, 1972b, pp. 241-266).

\section{The Ogan Model}

Similar to Flamholz, Ogan shaped a model in which some of the most important variables influencing the value of an individual in an organization are defined. The model aims at evaluating human capital especially in those service enterprises where market-determined prices are not in use. Prices of some services, for example, are determined by professional associations such as bar associations, medical associations, etc.. This is a combined model since it includes both monetary and non-monetary measures. The basic idea of the model is to measure the amount of a company's long-term benefit from an employee. The value that an employee has for the company should equal the employee's long-term benefit resulting from his/her employment. This long-term benefit is determined by two factors, namely:

(1) the direct benefit of an employee on the account of his employment;

(2) the certainty of his employment.

The direct benefit of an employee is the sum of all expected benefits resulting from his employment. Employment certainty indicates the level of probability that the employment remains permanent. The value of an employee for the company is obtained by multiplying the values of both factors (Ogan, 1976, p. 311).

\section{Monetary Models of Human Capital Evaluation}

Among monetary models of human capital evaluation, the following are presented: the replacement costs model, the opportunity costs model, the discounted wages and salaries model, and originally created dynamic model.

\section{The Replacement Costs Model}

The replacement costs model was developed by Flamholz in 1973. The author acknowledges two concepts of replacement costs: individual and positional. Individual replacement costs are defined as a current sacrifice that is mandatory if one wants to replace an individual of particular capacity with someone (an individual) or something (a machine) of the same capacity. These costs reflect the value of an individual for a company.

However, the value of an individual largely depends on his current and future position in a company (achieved due to his capacity). The author defines positional replacement costs as those resulting from replacing the particular mandatory services of each employee in a particular work position (workplace) in a company (Flamholz, 1973, p. 11).

The usage of this model is limited. The model requires not only an evaluation of the amount of costs stemming from replacing an employee with someone or something, but also an evaluation of the probability that another employee (or machine) will accomplish the same work. Additionally, evaluating the amount of replacement costs of all employees is a rather difficult task.

\section{The Opportunity Costs Model}

The opportunity costs model was developed by Hekimian and Jones in 1967. The basis of this model is composed of the opportunity costs of an employee — costs that reflect the value of an employee shown in case of 
using his alternative. Opportunity costs are defined as costs of lost benefits in a situation when an employee performs another task and/or as costs resulting from acquisition of the needed employee (Hekimian \& Jones, 1967, pp. 108-110). According to this definition, an employee has a certain value only if he/she is an exceptional resource, namely, when his/her movement from department A to department B causes lack of labour force in department A. The main weakness of this model is that it does not recognize the possibility of acquiring certain work abilities by employing new people.

\section{The Discounted Wages and Salaries Model}

The discounted wages and salaries model was developed by Lev and Schwartz (1971). According to this model, the value of human capital is defined as the present value of anticipated (future) remuneration of employees corrected for performance ratio. The performance ratio of employees is defined as the ratio between the company's rate of return and the average rate of return in the economy. Positive correction of the present value of anticipated remuneration of employees occurs when a company's rate of return is larger than the average rate of return in the economy, and the contrary, negative correction of the present value of anticipated remuneration of employees occurs when a company's rate of return is lower than the average rate of return in the economy (Lev \& Schwartz, 1971). Therefore, the underlying assumption is that the future value of employees' work may be evaluated by the amount of their wages and salaries.

\section{The Dynamic Model}

The dynamic model is based on the economic concept of value. According to this model, the value of particular goods depends on the present and future benefits associated with these goods. This also applies to employees. Therefore, the value of employees depends on the present value of their expected future services. This definition may apply to an individual as well as to all employees within a company. Therefore, this model is intended to evaluate:

(1) individual employees;

(2) groups of employees (i.e., all employees within a company).

The value of individual employees may be determined directly, while the value of a group of employees may be determined indirectly, as a corrected sum of values of individual employees. Correction is made via a coefficient of employee performance that is based on the ratio between added values within the company and the global economy for the last three years. Here it must be pointed out that the value of the group of employees is not a simple sum of the values of individual employees-This value usually differs from such a sum due to synergetic effects.

The model is a dynamic one, which means that it enables the establishment of the value of an individual employee or all employees within a company at any moment. It is based on an approach usually used for evaluating the majority of tangible fixed assets by recognizing some specific features of employees.

Some may find the comparison of tangible fixed assets and employees unsuitable, morally disputable or even offensive. Take apologies in advance for any misunderstandings. Human resources are treated as assets not to underestimate their human characteristics, but to emphasize their economic value. It means that human resources are treated as economic goods. 


\section{Evaluating Individual Employees}

As was already mentioned above, this model originally aims at evaluating individual employees. It was also mentioned that the value of a group of employees may be determined indirectly, as a corrected sum of values of individual employees. The dynamic model for evaluating individual employees is presented in Figure 1. Concepts and other items from the model are explained below.

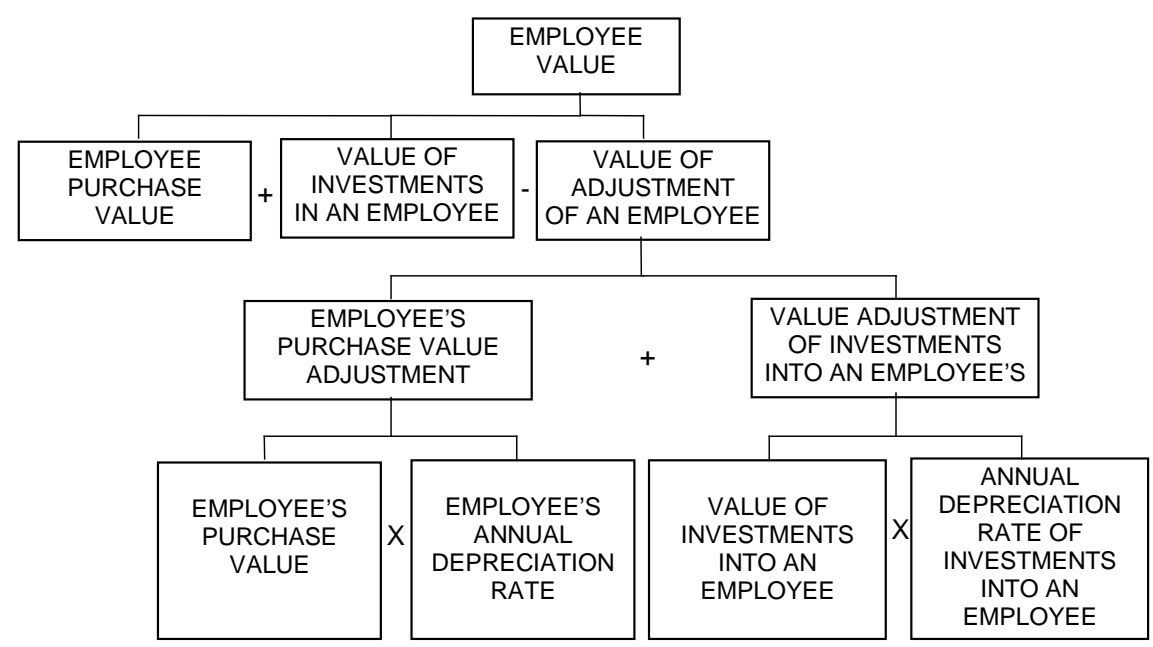

Figure 1. The dynamic model for evaluating individual employees.

\section{The Purchase Value}

The purchase value of tangible fixed assets normally equals the investment value associated with their acquisition. It is composed of the purchase price along with costs in relation to customs duties, transport, assembly and similar.

The purchase value of an employee is composed of investments into an employee before and directly upon his/her arrival at a company. The company does not necessary participate in all components of these investments. In the context of this evaluation model, the purchase value of an employee includes three components, namely:

(1) investments in employee training;

(2) investments in employee acquisition;

(3) employee opportunity costs.

Investments in employee training are associated with acquiring his/her work capacity. In this context, investment value is associated with primary school, high school, and university education. Investment value associated with training an employee to perform certain tasks may be defined as the usual investment needed in the process of acquiring his/her work capacity. Investment value associated with training an employee does not depend on the method of acquiring an employee. It means that the value of this investment is not subject to change when equally trained employees are of concern. An assumed value, obtained from the sum of investments needed for an employee in the process of acquiring relevant work capacity, may serve as investment value associated with employee training.

Investments in employee acquisition include:

(1) investments in job advertisement;

(2) investments in direct employee acquisition. 
Investments in job advertisement are associated with: placing ads for an available position, interviews, evaluation of candidate suitability, etc.. Investments in direct employee acquisition are associated with the medical assessment of an employee, his/her placement, etc..

Opportunity costs are lost benefits resulting from choosing a particular alternative. Employee opportunity costs are an individual's investments into his/her own knowledge and development. It is assumed that someone is in the position of employing a university graduate. This is an individual who has successfully accomplished his/her education on all three levels: primary, secondary, and tertiary.

Learning is time consuming (since it is measured in years) and tiresome. However, the results of the lasting efforts put into one's studies are not tangible material goods, but acquired knowledge and a diploma. Therefore, the decision for an education forces the employee to decline remunerations that would be collected in the case of him/her being employed during the time of study. The lost remunerations of an employee are, therefore, the opportunity costs that reflect the value of an individual's investments into his/her knowledge and development. Their value is the lowest at the primary school level and increases with additional years of study.

\section{Value Adjustment}

The value adjustment of a tangible fixed asset is a value of a fixed asset that is, via its usage, transferred to business effects. This value depends on the purchase value of a tangible fixed asset and its useful life. The value adjustment of an employee is a value transferred by an employee, via his/her co-operation in a business process to business effects. It may be obtained by calculating the sum of an employee's purchase value adjustment and the value adjustment of investments into an employee. The calculation is presented below:

$\begin{array}{ll}\text { value } & \begin{array}{l}\text { employee's } \\ \text { adjustment } \\ \text { of an employee }\end{array} \\ \text { purchase value } \\ \text { adjustment }\end{array} \quad \begin{aligned} & \text { value adjutment } \\ & \text { of investments } \\ & \text { into an employee }\end{aligned}$

The employee's purchase value adjustment is obtained by multiplying the employee's purchase value by his annual depreciation rate. The calculation is presented below:

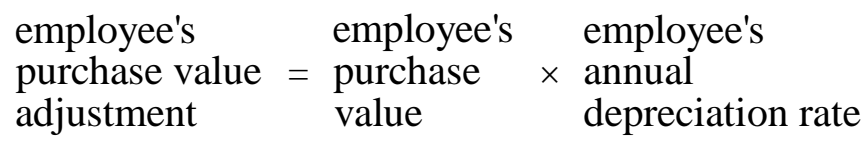

The annual depreciation rate of an employee is obtained by dividing 1 by his/her useful life expressed in years. The useful life of an employee, expressed in years, is the period during which the employee shall render services to the company. This period depends on the expected presence of the employee in a business process. However, there is a significant difference between a tangible fixed asset and an employee. If ownership is considered in the classical way, one may quickly figure out that an employee is not owned, since he/she is free to leave a company. Therefore, the useful life of an employee is the period during which it is reasonably expected that the employee shall render services to the company. It is a period from the present to the day when an employee quits working for a company because of finding employment elsewhere, retirement or similar reasons.

The value adjustment of investments into an employee is obtained by multiplying the value of investments into an employee by the annual depreciation rate of these investments. The calculation is presented below: 


$$
\begin{array}{ll}
\begin{array}{l}
\text { value adjustment } \\
\text { of investments } \\
\text { into an employee }
\end{array} & \begin{array}{l}
\text { value } \\
\text { of investments } \\
\text { into an employee }
\end{array} \times \begin{array}{l}
\text { annual depreciation rate } \\
\text { of investments } \\
\text { into an employee }
\end{array}
\end{array}
$$

Investments in employee acquisition include:

(1) investments in direct assurance of working abilities;

(2) investments in health and well-being;

(3) investments in loyalty to the company.

Investments in direct assurance of an employee's working abilities are those that are most profoundly relative to the employee's work in a company. They include: investments into formal and informal training and introductory training, the lower productivity of an employee during the period of his/her introductory training, and the lower productivity of an employee prior to his/her leaving the company (the opportunity costs of the company).

Investments into health and well-being are those that enable regular attendance in the workplace. They include: periodic employee medical check-ups, co-financing the lease of recreational buildings, organizing sport events and similar.

Investments into employee loyalty reduce the probability that an employee will quit working for the company due to disability, retirement or similar reasons.

The remaining item to be defined is the annual depreciation rate of investments into an employee. This rate may be obtained by dividing 1 by the useful life of investments into an employee (expressed in years) as shown below:

$$
\begin{aligned}
& \text { annual depreciation } \\
& \text { rate of investments } \\
& \text { into an employee }
\end{aligned}=\frac{1}{\text { useful life of investments into an employee (in years) }}
$$

The useful life of investments into an employee is a period during which the employee shall render services to the company as result of investments directed toward his/her employment. The duration of this period depends on the intensity of knowledge-obsolescence and varies across employees. The knowledge-obsolescence of employees with a technical education depends on the technical/technological development in a particular economic area while the knowledge-obsolescence of an employee graduating in the social sciences depends more on scientific development in that particular area and similar.

\section{The Net Carrying Amount}

The net carrying amount of a tangible fixed asset is the positive difference between its purchase value and its adjusted value. It is a value that shall be transferred by a tangible fixed asset to business effects during its remaining useful life.

Similarly, the net carrying amount of an employee depends on two factors, namely:

(1) the previously determined positive difference between the purchase value of an employe and his/her adjusted value;

(2) his/her significance to a company. 
The value of an employee to a company depends on his/her position in the company in terms of its organizational structure. Of course, this also influences his/her remuneration. The wages and salaries of employees are, therefore, important indicators of their value within the company. Employee wages and salaries may be defined as a factor that reflects the efficiency of the used work abilities of an individual in the company. An employee, with his/her presence in a business process, offers the company a service and receives a salary in return. The salary amount reflects the value of services offered by an individual to a company and also the employee's value to the company.

According to the above, the net carrying amount of the value of an employee must be corrected. The correction factor in this context is the ratio between the annual salary of an employee in a company and the average annual salary of an employee in a national economy. The correction factor may be defined as follows:

$$
\text { annual salary of an employee in a company }
$$

average annual salary of an employee in a national economy

\section{Evaluating a Group of Employees}

The value of a group of employees is not a simple sum of the values of individual employees-this value usually differs from such a sum due to synergetic effects.

However, a certain relationship between the sum of values of individual employees and the value of a group of employees exists. The model assumes that this relationship depends on the successful performance of employees in the company compared with the successful performance of employees in an entire economy.

The employees' performance coefficient serves as a measure of the successful performance of employees. It is defined as the ratio between the sum of weighted average added value per employee in a company and the entire economy during last three years (numerator) and the sum of the number of years used (denominator). The aforementioned ratio of last year is then multiplied by a factor of 3 , the ratio of two years ago by a factor of 2 , and the ratio of three years ago by a factor of 1 . The sum of the factors $(3+2+1)$ equals 6 . Accordingly, the performance coefficient is calculated as follows:

$$
\text { employees' performance coefficient }=\frac{3 \cdot \frac{\mathrm{AA} 0}{\mathrm{BB} 0}+2 \cdot \frac{\mathrm{AA} 1}{\mathrm{BB} 1}+\frac{\mathrm{AA} 2}{\mathrm{BB} 2}}{6}
$$

Abbreviations in the equation mean:

$\mathrm{AAO}$ — added value per company employee during last year;

$\mathrm{BBO}$ — added value per employee in entire economy during last year;

AA1—added value per company employee two years ago;

BB1—added value per employee in entire economy two years ago.

The remaining two abbreviations in the equation are defined by using the same logic as above.

When the value of a group of employees is to be determined, the aforementioned approach enables recognition of the overall performance of a company for a period longer than a year. When calculating, the period selection is a matter of subjective judgment, however a three-year period seems to be suitable. The business life of a company is rather intensive, and in light of this, three years seems to be a period that is long enough. In 
addition, the overall performance of a company during the last year is more accentuated than the performance of previous years.

\section{Conclusions}

Employees are economic goods, and therefore their value must be known. Knowing this value is crucial for more realistic company financial statements and for anyone who wishing to manage human resources efficiently. For this purpose, an appropriate methodological framework for evaluating people is needed, i.e., estimating the value of a company's human capital.

There exist two groups of models for human capital evaluation: monetary and non-monetary models. Non-monetary models are not appropriate for disclosing human capital among the assets on a balance sheet and most popular monetary models are not appropriate for general use-They can be used only in limited cases.

According to these lines the original model for human capital evaluation named dynamic model was developed. This is the firs step towards development a general model for evaluation human capital of employees.

\section{References}

Brooking, A. (1996). Intellectual capital. London: International Thomson Business Press.

Edvinson, L., \& Malone, M. S. (1997). Intellectual capital: Realizing your company's true value by findings its hidden roots. New York: HarperCollins Publishers Inc..

Edvinson, L., \& Sullivan, P. (1996). Developing a model for managing intellectual capital. European Management Journal, 14(4), 356-364.

Flamholz, E. G. (1972a). Assessing the validity of a theory of human resource value: A field study. Journal of Accounting Research, 10(3), 241-266.

Flamholz, E. G. (1972b). Toward a theory of human resource value in formal organisations. The Accounting Review, 47(4), 666-678.

Flamholz, E. G. (1973). Human resource accounting: Measuring positional replacement costs. Human Resource Management, 12(1), 8-16.

Flamholz, E. G. (1982). State-of-the-art and future prospects. Encino: Dickenson.

Hekimian, J. S., \& Jones, C. H. (1967). Put people on your balance sheet. Harvard Business Review, 43(2), 105-113.

Lev, B., \& Schwartz, A. (1971). On the use of the economic concept of human capital in financial statements. The Accounting Review, 46(1), 103-112.

Likert, R., Bowers, D. G., \& Norman, R. M. (1969). How to increase the firm's lead time in recognising and dealing with problems of managing its human organisation. Michigan Business Review, 22(2), 617-632.

Ogan, P. (1976). A human resource value model for professional service organisations. The Accounting Review, 14(2), $195-217$.

Sawalia, B. V. (1999). Human resource accounting practices in public undertakings in India. The Management Accountant, 34(8), 575-582. 